\title{
Thin film techniques for solid oxide fuel cells
}

\author{
V.E.J. van Dieten and J. Schoonman \\ Laboratory for Inorganic Chemistry, Delft University of Technology. Julianalaan 136, 2628 BL Delft. The Netherlands
}

Received 21 October 1991; accepted for publication 25 October 1991

\begin{abstract}
Electrochemical vapor deposition (EVD) is a key technology for making thin layers of the solid electrolyte as well as the interconnection material of the solid oxide fuel cell (SOFC). In addition to EVD several advanced deposition techniques for SOFC components and SOFC stacks have recently been reported. Among these techniques are thermal spraying and laser spraying techniques, while the chemical aerosol deposition technology holds promise for utilisation in SOFC technology. One of the major drawbacks of gas-phase deposition techniques is the low growth rate. To circumvent this problem a combination of the EVD process and thermophoresis assisted chemical vapor deposition (TA-CVD) has been developed by the present authors. This latter process is also referred to as particle precipitation aided-CVD (PP-CVD). With the PP-CVD technique growth rate increases in the order of 100-1000 can be achieved. The principles of these advanced deposition techniques will be reviewed. Characteristics of layers of SOFC components and SOFC stacks will be discussed.
\end{abstract}

\section{Introduction}

The fabrication techniques are very important in commercializing SOFC reactors. The fabricated components must fulfill their requirements and the techniques used must be as simple as possible, be fast and have moderate costs. The choice of the SOFC design, tubular, planar or monolithic, also influences the fabrication methods to be used, e.g. tubular components cannot be fabricated by tape casting.

The research and development of SOFC reactors has led to the "state of the art" materials and fabrication methods listed in table 1 . New materials for electrodes, the electrolyte, and the interconnect are being investigated, but also a great effort is put into

Table 1

State of the art materials and fabrication methods for SOFC components.

\begin{tabular}{lll}
\hline Component & Material & Fabrication method \\
\hline electrolyte & $\mathrm{YSZ}\left(8-10 \mathrm{~mol}^{\circ}\right)$ & EVD, tape casting \\
interconnect & $\mathrm{Mg}$-doped $\mathrm{LaCrO}_{3}$ & EVD, tape casting \\
cathode & $\mathrm{Sr}$-doped $\mathrm{LaMnO}_{3}$ & $\begin{array}{c}\text { Slurry coating, } \\
\text { tape casting }\end{array}$ \\
anode & $\mathrm{Ni}-\mathrm{YSZ}$ & $\begin{array}{c}\text { Slurry coating, } \\
\text { tape casting }\end{array}$ \\
& &
\end{tabular}

the improvement and development of existing and new fabrication techniques in order to optimize the cell performance.

In this paper several advanced deposition techniques will be reviewed and the characteristics of layers of SOFC components will be discussed.

\section{Deposition techniques}

\subsection{Electrochemical vapor deposition}

EVD is a modified form of CVD, developed by Westinghouse [1], which utilizes an electrochemical potential gradient to grow thin, gas tight layers of either ionically or electronically conducting metal oxides on porous substrates. EVD is a two step process as is shown in fig. 1 . The first step involves pore closure by a normal CVD type reaction between the reactant metal chloride vapors and water vapor (or oxygen). Once the pores are closed the reactant vapors are no longer in direct contact with each other. Film growth then proceeds due to the presence of an electrochemical potential gradient over the deposited film. In this step oxygen ions formed on the water vapor side of the substrate diffuse through the thin metal oxide layer to the metal chloride side. Here the 


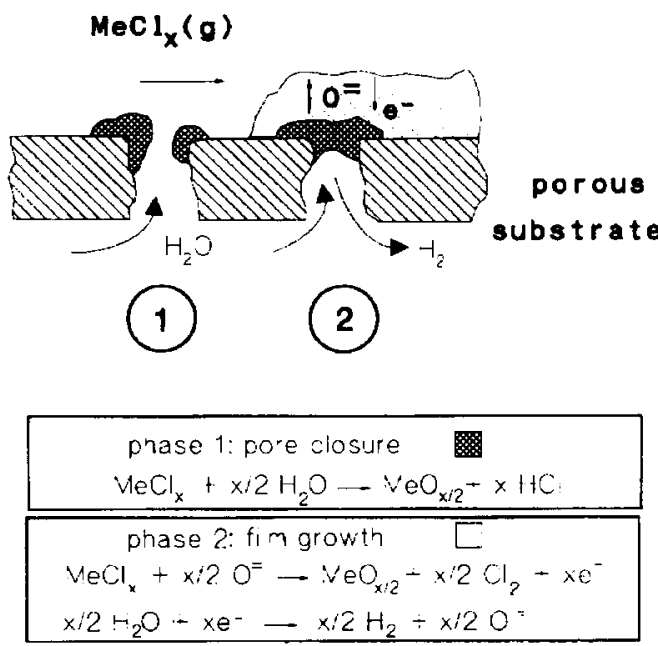

Fig. 1. The principle of electrochemical vapor deposition.

oxygen ions react with the metal chloride vapors to form the metal oxide product [ $1-3]$. The growth rate of the film can be controlled by the reactant concentration, reaction temperature and pressure. A detailed model of the EVD growth process is given elsewhere [3]. Disadvantages of the process are the high reaction temperature, the presence of corrosive gases, and the relatively low deposition rate.

Nowadays EVD is a key technology for depositing uniform gas-tight layers of YSZ and magnesium doped lanthanum chromite in tubular SOFC technology [1-8].

\subsection{Thermophoresis assisted CVD}

In thermophoresis assisted-CVD (TA-CVD) or particle precipitation aided-CVD (PP-CVD) powder particles are formed in the gas phase by a high supersaturation of the reactants, and deposited on a substrate. This precipitation is promoted by diffusion in a thermal gradient between the gas phase and the substrate $[9,10]$.

Residual reactant concentrations in the gas phase should be sufficiently high in the deposition zone to incorporate the particles in the deposit by a conventional CVD step. An increase in deposition rate of several orders of magnitude over deposition rates usually encountered in conventional CVD is thus realized by TA-CVD. Recently titanium nitride, aluminium nitride, titanium oxide, and zirconium ox- ide layers have been deposited using this technique $[10,11]$.

The deposition rates in TA-CVD are sufficiently high to offer an attractive alternative for the production of SOFC electrode materials. The advantage of this process is that the products are formed from gaseous reactants in a single process step, obviating intermediate ceramic processing stages such as powder tailoring, green product forming and high temperature sintering.

\subsection{Combination of EVD and TA-CVD}

For the deposition of thick $(>50 \mu \mathrm{m})$ gas tight layers EVD is a suitable technique. However, growth rates are so low that process times of several hours are required. A solution to this problem might be a combination of the EVD and TA-CVD processes, which has been proposed recently [12]. The principle of this combination is shown in fig. 2 . In the first step on a porous substrate, e.g. the cathode, a very thin gas-tight layer of the interconnection material is deposited by means of EVD. In the second step the oxygen source reactant, which, in the first step, is fed to the opposite side of the substrate as the metal chlorides, is brought in at the same side as the

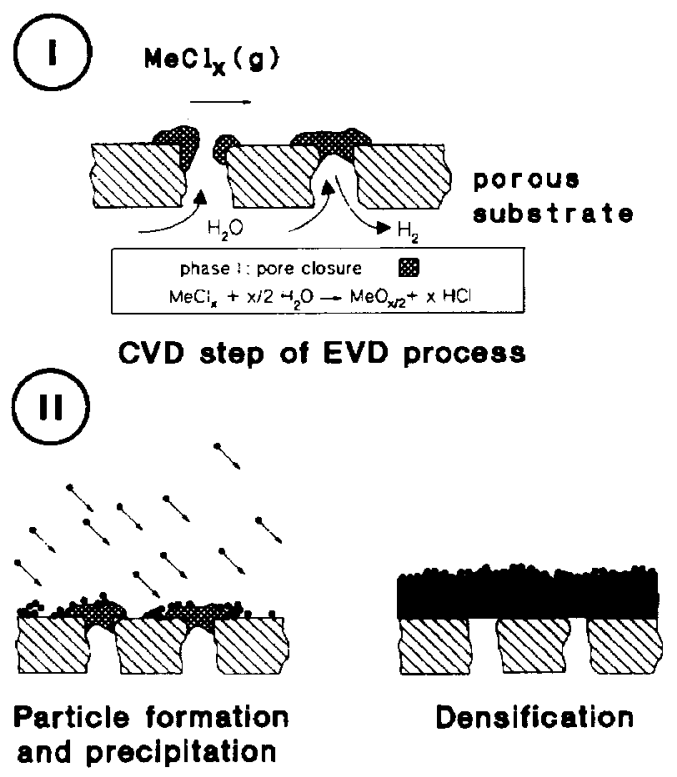

Fig. 2. The principle of the combination of the EVD and TACVD processes. 
metal chlorides. Furthermore the reaction conditions are changed so that powder formation will occur. The powder is collected on the gas-tight EVD layer by means of thermophoresis and subsequently densified by a chemical vapor infiltration process. The growth rate can be two orders of magnitude higher than in normal EVD. In this way the mechanical strength of the interconnection layer can be improved in a relatively short time, while the other properties remain unchanged [12].

\subsection{Chemical aerosol deposition technology}

Chemical aerosol deposition technology (CADT) differs from conventional CVD in the way the reactants are transported to the reaction zone. In CADT the reactants are dissolved in a liquid which is atomized and enter the reaction zone as an aerosol [13]. Depending on the process conditions various modes of aerosol decomposition can occur (fig. 3 ). In order to obtain crystalline films of high density, the mode which comes nearest to conventional CVD is required. This is the case with mode 4 , where in the end the reactants reach the substrate as a vapor.

The process is well suited for depositing thin layers $(0.1-5 \mu \mathrm{m})$ over large areas. The use of dissolved reactants in the form of an aerosol offers a

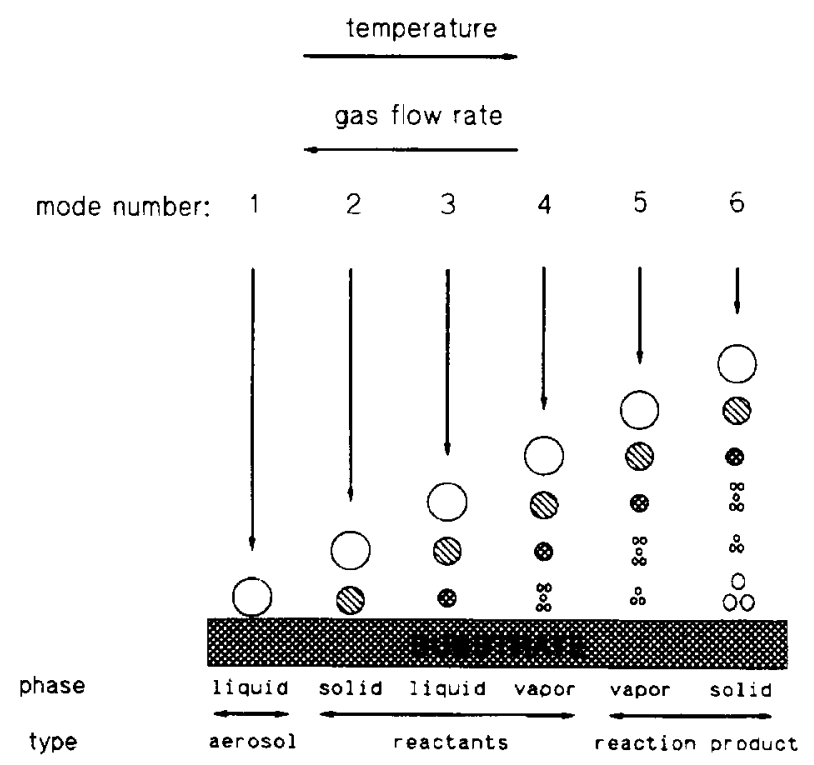

Fig. 3. Decomposition modes in CADT. The phase and type of the particles reaching the substrate are presented in ref [18]. greater freedom of choice. This often makes it possible to keep the substrate temperature in the range of $300-600^{\circ} \mathrm{C}$, which is considerably lower than in other CVD techniques. Recently CADT has been used to deposit transparent conductive indium-tin oxide layers [14], and zinc oxide and zinc sulfide layers [15].

One of the main problems in CADT is controlling the aerosol properties, i.e. producing the desired amount of fine aerosol particles with a narrow size distribution. Such an aerosol results in a homogeneous vapor phase near the substrate.

Film density can be improved by charging the aerosol particles in a corona-discharge (corona-aided CADT) [15]. In this way the particles can be accelerated by an electric field and so the time the particles stay in the hot temperature region can be controlled. Zinc sulfide films with a density of about $80 \%$ have been deposited.

Although there have been no reports on the use of CADT for the fabrication of SOFC components this deposition technique might become an attractive alternative for the techniques used nowadays.

\subsection{Laser spraying}

Laser spraying is a physical deposition (PD) technique. In PD techniques the starting material, a powder or an aerosol, is not evaporated. It reaches the substrate as a solid or a liquid. PD techniques are generally used to apply coatings on a substrate which might otherwise be damaged by the high temperatures used in other coating techniques. Substrate temperatures are relatively low $\left(200-700^{\circ} \mathrm{C}\right)$. In order to obtain dense layers often a subsequent heat treatment is required. In that case the advantage of low substrate temperatures does not apply.

The laser spraying technique uses a carbon dioxide laser beam which is passed parallel to the substrate $[16,17]$. This parallel arrangement prevents any damage to the substrate. The powder which is supplied through an accurate powder supply device (sometimes with the help of a carrier gas) melts in the laser beam and adheres to the substrate. The environment where the spraying takes place can be adjusted to the conditions needed. The process is controlled by the laser power density, substrate temperature, reaction or carrier gases and reactor 
pressure. The substrate can be heated by an auxiliary heater or with part of the laser beam.

\section{Characteristics of YSZ films}

Isenberg [1] and Lin et al. [6] observed linear growth rates in EVD of YSZ films ranging from 1.5 $\mu \mathrm{m} / \mathrm{h}$ at $1000^{\circ} \mathrm{C}$ to $6.5 \mu \mathrm{m} / \mathrm{h}$ at $1125^{\circ} \mathrm{C}$. With these growth rates it is possible to deposit $30-50 \mu \mathrm{m}$ thick layers in a few hours. The linear growth rates are the result of diffusion limitation of oxygen or the oxygen source reactant in the substrate pores [8]. In case the film growth is governed by solid state diffusion, growth kinetics are similar to the Wagner oxidation of metals. The growth rate obeys the parabolic rate law:

$L^{2}=2 K t+C_{0}$,

in which $L$ is the layer thickness and $K$ the parabolic rate constant. In YSZ, an ionically conducting material, the growth rate is governed by electronic transport [3]. The parabolic rate constant ranges from $0.0092 \mu \mathrm{m}^{2} / \mathrm{s}$ at $1000^{\circ} \mathrm{C}$ to $0.37 \mu \mathrm{m}^{2} / \mathrm{s}$ at $1200^{\circ} \mathrm{C}$, which corresponds to average growth rates of $8 \mu \mathrm{m} / \mathrm{h}$ to $50 \mu \mathrm{m} / \mathrm{h}$ for the first hour [2,5].

EVD layers are assumed to be dense and gas tight. According to Isenberg [1] water and acetone did not penetrate a YSZ layer after $15 \mathrm{~min}$ of deposition. This shows that pore closure times can be in the order of ten minutes. Typically pore closure times vary between 10 and $60 \mathrm{~min}$. [1,6,18].

The open circuit voltage (OCV) of a La$\mathrm{MnO}_{3}|\mathrm{YSZ}| \mathrm{Ni}-\mathrm{YSZ}$ cell with an EVD layer of YSZ was reported to be $1.00 \mathrm{~V}$. This is close to the theoretical value of $1.04 \mathrm{~V}$ indicating that there was very little gas leakage through the electrolyte [4]. Reported resistivity of EVD grown YSZ is $12 \pm 6 \Omega \cdot \mathrm{cm}$ at $1000^{\circ} \mathrm{C}[19]$.

Thick YSZ layers of 60-150 $\mu \mathrm{m}$ were deposited using the laser spraying technique [16,17]. The crystal structure of the coatings was the same as that of the original powder. No data are available of the density of the layers or of cell performance.

\section{Interconnect fabrication}

For the fabrication of the interconnection material EVD and tape casting seem to be the only two well developed fabrication methods. The principles of EVD of lanthanum chromite and $\mathrm{YSZ}$ are very much alike. The same parabolic rate law of film growth was found [8], indicating that EVD of lanthanum chromite can also be controlled by solid state diffusion. In lanthanum chromite, an electronically conducting material, it is the oxygen ion diffusion via oxygen vacancies in the growing film which is rate limiting. Doping of the lanthanum chromite with magnesium increases the oxygen vacancy concentration and hence the growth rate [7]. Pal and Singhal [8] found a parabolic rate constant of $0.18 \mu \mathrm{m}^{2} / \mathrm{s}$ at $1300^{\circ} \mathrm{C}$, which corresponds to an average growth rate of $36 \mu \mathrm{m} / \mathrm{h}$ for the first hour.

Disadvantage of the production of the interconnection material by EVD is the very high deposition temperature. That is why it is interesting to investigate the possibility to apply one of the other deposition techniques discussed earlier to the interconnection material.

\section{References}

[1] A.O. Isenberg, ECS Symp. Electrode Materials, Processes for Energy Conversion and Storage, Vol. 77-6 (1977) p.572.

[2] M.F. Carolan and J.N. Michaels, Solid State Ionics 37 (1990) 189.

[3] J. Schoonman, J.P. Dekker, J.W. Broers and N.J. Kiwiet, Solid State Ionics 46 (1991) 299

[4] A.O. Isenberg, ECS Symp. Electrode Materials, Processes for Energy Conversion and Storage, Vol 77-6 (1977) p. 682.

[5] U.B. Pal and S.C. Singhal, J. Electrochem. Soc. 137 (1990) 2937.

[6] Y.S. Lin, L.G.J. de Haart, K.J. de Vries and A.J. Burggraaf, J. Electrochem. Soc. 137 (1990) 3960.

[7] W. Feduska, A.O. Isenberg, J.E. Bauerle, W.J. Biter, W. Ichikawa, P.J. Nalepa, R.J. Ruka, L.N. Yannopoulos and S.A. Zeitman, DOE report EY-76-C-03-1197 (1978) p. 47.

[8] U.B. Pal and S.C. Singhal, J. High Temp. Sci. 27 (1990) 251.

[9] H. Komiyama, US Patent, US 4.654.228 (1987).

[10] J.P. Dekker, P.J, van der Put, R.R. Nieuwenhuis, H.J. Veringa and J. Schoonman, J. Phys. IV, Coll. C2, Suppl. J. Phys. II, 1 ( 1991 ) C2-593.

[11] H. Komiyama, T. Osawa, Y. Shimogaki, N. Wakita, M. Minamiyama and T. Ueoka, Proc. 10th Intern. Conf. on CVD (1987) p. 1119. 
[12] J. Schoonman and A. Mackor, patent application NL 89.03125 (1989).

[13] P.V. Lambeck, L. Hilderink and Th.J.A. Popma, 2nd Intern. Aerosol Conf., Berlin (1986) p. 964.

[14] F.J. Garcia, J. Muci and M.S. Tomar, Thin Solid Films 97 (1982) 47.

[15] D. Maatman, W. Gruisinga, P.V. Lambeck and Th.J.A. Popma, J. Aerosol Sci. 19 (1988) 1369.

[16] K. Tsukamoto, F. Uchiyama, Y. Ohno and Y. Kaga, Surface Eng. 6 (1990) 45 .
[17] K. Tsukamoto, F. Uchiyama, Y. Kaga, Y. Ohno, T. Yanagisawa, A. Monma, Y. Takahagi, M.J. Lain and T. Nakajima, Solid State Ionics 40/41 (1990) 1003.

[18] M.F. Carolan and J.N. Michaels, Solid State Ionics 25 (1987) 207.

[19] H.S. Isaacs, P.G. Russel and L.J. Olmer, ECS Symp. Electrode Materials, Processes for Energy Conversion and Storage, Vol. 77-6 (1977) p. 584 